\title{
МЕТОДЫ ПОЛЕВЫХ И ЛАБОРАТОРНЫХ ИССЛЕДОВАНИИ ЛЕДНИКОВЫХ ОТЛОЖЕНИЙ В СТРАНАХ ЕВРОПЫ И СЕВЕРНОЙ АМЕРИКИ
}

Изучение ледниковых отложений дает богатейшую информацию для решения генетических, стратиграфических и палеогеографических вопросов и некоторых задач прикладного характера. К сожалению, в ведомствах и учреждениях разных стран, занимающихся изучением ледниковых отложений, методы проведения полевых и лабораторных работ, а также способы обработки и наглядного отображения данных настолько отличны друг от друга, что получаемые результаты не поддаются ни обобщению, ни сопоставлению. В ряде стран неоднократно предпринимались попытки унифицировать структурную классификацию обломочных пород и некоторые приемы аналитических работ, однако они не увенчались успехом, поскольку при этом недостаточно учитывались специфика исследований, их направленность и далеко не всегда в основу брались результаты целевых методических работ.

Начиная с 1972 г. в усовершенствование и унификацию полевых и лабораторных методов изучения ледниковых отложений активно включилась Комиссия по генезису и литологии четвертичных отложений Международного союза по изучению четвертичного периода (ИНКВА). В рамках этой Комиссии была создана под руководством А. Раукаса рабочая группа и поставлены перед ней следующие задачи:

установить. применяемые в настоящее время методы изучения ледниковых отложений в разных странах;

выявить наиболее эффективные методы и вести их пропаганду;

выработать рекомендации для унификации методов сбора и обработки фактического материала, а также основных гранулометрических границ с тем, чтобы получать однородные и легко сопоставимые данные.

В целях решения первой задачи был составлен и разослан вопросник в адрес стран Северной Америки и Европы, где ледниковые образования широко распространены. Было получено и обобщено более 200 ответов от геологов, географов, инженеров-геологов и почвоведов из США, Канады, а также из Норвегии, Швеции, Финляндии, СССР, Англии, Голландии, ФРГ, Польши, Чехословакии и Швейцарии, отражающих мнение около 1000 исследователей. Анализ этих ответов показал, что в методах исследования существуют серьезные разногласия, причем даже среди специалистов одной и той же профессии и одного и того же учреждения, не говоря уже о разных странах.

В данном сообщении мы освещаем результаты анализа ответов. Это позволит оценить уровень изучения ледниковых отложений на обоих континентах. 


\section{Полевые исследования}

Полевые работы в большинстве случаев механизированы весьма слабо (табл. 1), особенно у почвоведов и географов. Образцы отбираются чаще всего с помощью лопаты и кирки. Механизированное бурение практикует примерно половина ответивших. Роющие машины либо совсем не используются, либо используются крайне редко. Геофизическая аппаратура находит ограниченное применение. Геотехнические определения в полевых условиях выполняют лишь инженеры-геологи, реже гидрогеологи и почвоведы. Превалируют описания на основе визуальных наблюдений (цвета, гранулометрического состава, плотности, степени выветривания и т. д.). Обломки крупностью больше галечной размерности изучаются преимущественно в странах Балтики. Окатанность, ориентировка обломков и литологический состав определяются в основном в галечной фракции.

В Европе всего лишь 14,3\% исследователей используют при определении окраски отложений специальные шкалы. В Северной Америке их больше - 56,6\% (табл. 1). На обоих континентах нанболее популярной

Таблица 1

Использование полевых методов исследования, \%

\begin{tabular}{|c|c|c|c|c|c|c|c|c|}
\hline \multirow{2}{*}{ Методы и аппаратура } & \multicolumn{2}{|c|}{ Обычно } & \multicolumn{2}{|c|}{ Часто } & \multicolumn{2}{|c|}{ Редко } & \multicolumn{2}{|c|}{$\begin{array}{l}\text { Никогда не } \\
\text { исполь- } \\
\text { зуются }\end{array}$} \\
\hline & $\begin{array}{l}\text { Сев. } \\
\text { Аме- } \\
\text { рика }\end{array}$ & $\begin{array}{l}\text { EB- } \\
\text { pona }\end{array}$ & $\begin{array}{l}\text { Сев. } \\
\text { Аме- } \\
\text { рика }\end{array}$ & $\begin{array}{c}\text { Eв- } \\
\text { pona }\end{array}$ & $\begin{array}{l}\text { Сев. } \\
\text { Аме- } \\
\text { рика }\end{array}$ & $\begin{array}{l}\text { Ев- } \\
\text { ропа }\end{array}$ & $\begin{array}{l}\text { Cев. } \\
\text { Аме- } \\
\text { рика }\end{array}$ & $\begin{array}{l}\text { Eв- } \\
\text { poпа }\end{array}$ \\
\hline Механизированное буре & 28 & 27,3 & 21,7 & 17,4 & 20,5 & 28,9 & 9 & 26,4 \\
\hline $\begin{array}{l}\text { Роющие машины (экскават } \\
\text { ры) } \\
\text { Геофизическая аппаратура }\end{array}$ & 9,6 & 14,5 & 10 & $1:$ & & 29 & 4 & 41,9 \\
\hline еления & $\begin{array}{r}6,0 \\
1,2 \\
2,4 \\
14,4\end{array}$ & $\begin{array}{r}4,7 \\
2,1 \\
7,4 \\
13,5\end{array}$ & $\begin{array}{r}6,0 \\
9,6 \\
6,0 \\
19,3 \\
9,6\end{array}$ & & $\begin{array}{r}9,6 \\
9,6 \\
2,4 \\
13,2 \\
22,9\end{array}$ & $\begin{array}{r}3,4 \\
20,2 \\
5,4 \\
32,0 \\
12,2\end{array}$ & $\begin{array}{l}83,1 \\
65,0\end{array}$ & $\begin{array}{l}89,8 \\
67,1 \\
91,1 \\
45,7 \\
55,4\end{array}$ \\
\hline $\begin{array}{l}\text { iреде. } \\
\text { в п } \\
\text { на }\end{array}$ & & $\begin{array}{r}55 \\
4\end{array}$ & & & & & & $\begin{array}{l}15 \\
15\end{array}$ \\
\hline $\begin{array}{l}\text { с использованием стандар. } \\
\text { тов }\end{array}$ & 56,6 & 14,3 & 4 & 12 & 2 & $\rho$, & 38 & 66. \\
\hline Визуальные структурные опре- & 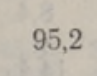 & 61,6 & 1 & 1 & 2,4 & 22,2 & 1,2 & \\
\hline Визуальные текстурные опреде- & 60,2 & 5 & 2 & 29,6 & 10,8 & 3,5 & 7,2 & 10 \\
\hline $\begin{array}{l}\text { Определения степени выветри- } \\
\text { вания } \\
\text { Определение орнентировки об- }\end{array}$ & 81,9 & 61,1 & 15,7 & & & 9,8 & 1,2 & \\
\hline $\begin{array}{l}\text { Определение орнентировки об- } \\
\text { ломков }\end{array}$ & 34,9 & 23,9 & 33,7 & 28,3 & 18,1 & 31,6 & 13,2 & 16 \\
\hline пределение окатанности об- & 38,5 & 20,4 & 32,5 & 31,8 & 19,3 & 34,5 & 9,6 & 13 \\
\hline $\begin{array}{l}\text { ранулометрический анали } \\
\text { грубых фракций } \\
\text { пределение петрографическог }\end{array}$ & 28,9 & 23,7 & 21,7 & 22,8 & 27,7 & 18,4 & 21,7 & 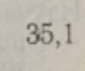 \\
\hline $\begin{array}{l}\text { ение петрографическ } \\
\text { а обломков } \\
\text { e руководящих валу } \\
\text { e поверхности обл }\end{array}$ & 4 & $\begin{array}{l}40, \\
27,\end{array}$ & 30,1 & & & & 21 & 18 \\
\hline $\begin{array}{l}\text { Изучение поверхности облом } \\
\text { ков } \\
\text { Палеонтологические исследова }\end{array}$ & 18,1 & 14,3 & 24,1 & 32,9 & 30,1 & 17,1 & 27,7 & Ju \\
\hline $\begin{array}{l}\text { Іалеонтологические иссле } \\
\text { ния }\end{array}$ & 21,7 & 14,1 & 14,4 & 25,9 & 30,1 & 24,7 & 33,7 & 30 \\
\hline
\end{tabular}

2 ENSV TA Toimetised. G 21979 
является шкала Мансела. К сожалению, определения цвета выполняются на природном сыром материале чаще, чем на высушенном, что делает их субъективными и трудно сравнимыми.

Наиболее распространенный способ опробования - точечные пробы. В Европе их не использует лишь $6,8 \%$ и в Северной Америке 2,4\% исследователей. Вертикальные борозды закладываются редко, горизонтальные еще реже. Длина борозд обычно составляет 50-100 см, в 25\% случаев 20-50 см. Образцы для лабораторных анализов отбираются весом 50 - 200 г, хотя бывают и свыше 1 кг $(8,6 \%$ ответов из Европы и $12 \%$ из Северной Америки). Конечно, размер образцов и длина борозд выбираются в зависимости от решаемой задачи.

\section{Лабораторные исследования}

В лабораторных условиях многие исследователи ограничиваются гранулометрическими определениями (табл. 2). В Северной Америке верхней границей определения фракций считается 2 или 4 мм, в Европе 10 или 20 мм. Вес отбираемых для исследования образцов зависит от гранулометрического типа отложений, для мелкозема (менее 2 мм) он составляет 50-100 2, а для гравийной фракции может достигать $3 \kappa 2$.

Для иммерсионных минералогических анализов берутся размерные

Таблица 2

Использование лабораторных методов исследования, \%

\begin{tabular}{|c|c|c|c|c|c|c|c|c|}
\hline \multirow{2}{*}{ Метод } & \multicolumn{2}{|c|}{ Обычно } & \multicolumn{2}{|c|}{ Часто } & \multicolumn{2}{|c|}{ Редко } & \multicolumn{2}{|c|}{$\begin{array}{c}\text { Никогда не } \\
\text { исполь- } \\
\text { зуютея }\end{array}$} \\
\hline & $\begin{array}{l}\text { Сев. } \\
\text { Аме- } \\
\text { рика }\end{array}$ & $\begin{array}{c}\text { Eв- } \\
\text { ропа }\end{array}$ & $\begin{array}{l}\text { Сев. } \\
\text { Аме- } \\
\text { рика }\end{array}$ & $\begin{array}{l}\text { Eв- } \\
\text { pona }\end{array}$ & $\begin{array}{l}\text { Сев. } \\
\text { Аме- } \\
\text { рика }\end{array}$ & $\begin{array}{l}\text { Eв- } \\
\text { pona }\end{array}$ & $\begin{array}{l}\text { Сев. } \\
\text { Аме- } \\
\text { рика }\end{array}$ & $\begin{array}{c}\text { Eв- } \\
\text { pona }\end{array}$ \\
\hline Гранулометрический анализ & 77,1 & 81,4 & 13,2 & 11,0 & - & 6,8 & 9,6 & 6,8 \\
\hline $\begin{array}{l}\text { Литологнческие определения в } \\
\text { гравийной фракции } \\
\text { Минералогические определения }\end{array}$ & 25,3 & 28,2 & 18,1 & 41,2 & 18,1 & 16,5 & 38,6 & 44,1 \\
\hline $\begin{array}{l}\text { по фракциям } \\
\text { в песчаной } \\
\text { в пылеватой } \\
\text { в глинистой } \\
\text { Силикатный анализ } \\
\text { Палеомагнитные определения } \\
\text { Определение }\end{array}$ & $\begin{array}{r}42,2 \\
36,1 \\
33,7 \\
3,6 \\
4,8\end{array}$ & $\begin{array}{r}15,1 \\
19,8 \\
13,2 \\
10,8 \\
1,4\end{array}$ & $\begin{array}{r}24,1 \\
6,0 \\
24,1 \\
16,9 \\
8,4\end{array}$ & $\begin{array}{r}25,8 \\
20,9 \\
28,6 \\
24,3 \\
4,1\end{array}$ & $\begin{array}{r}10,8 \\
19,3 \\
20,5 \\
24,1 \\
8,4\end{array}$ & $\begin{array}{r}21,5 \\
9,9 \\
17,6 \\
22,5 \\
1,4\end{array}$ & $\begin{array}{l}22,8 \\
52,9 \\
21,6 \\
56,6 \\
77,2\end{array}$ & $\begin{array}{l}37,6 \\
49,4 \\
40,6 \\
42,4 \\
93,1\end{array}$ \\
\hline $\begin{array}{l}\text { Oпределение } \\
\text { карбонатности } \\
\text { органики } \\
\text { микроэлементов } \\
\text { адсорбированных ионов } \\
\text { окатанности зерен } \\
\text { физического вораста } \\
\text { границ Аттерберга } \\
\text { степени выветривания }\end{array}$ & $\begin{array}{r}27,7 \\
16,9 \\
6,0 \\
9,6 \\
13,2 \\
13,2 \\
18,1 \\
25,3\end{array}$ & $\begin{array}{r}27,9 \\
22,1 \\
17,1 \\
7,7 \\
15,1 \\
9,6 \\
25,3 \\
5,5\end{array}$ & $\begin{array}{r}14,4 \\
16,9 \\
16,9 \\
6,0 \\
30,1 \\
19,3 \\
26,5 \\
16,9\end{array}$ & $\begin{array}{l}44,5 \\
32,6 \\
14,5 \\
20,5 \\
25,9 \\
15,0 \\
13,3 \\
12,3\end{array}$ & $\begin{array}{r}10,8 \\
22,9 \\
14,8 \\
8,4 \\
16,9 \\
14,4 \\
10,8 \\
14,4\end{array}$ & $\begin{array}{r}20,7 \\
20,0 \\
15,8 \\
19,2 \\
32,2 \\
5,5 \\
16,0 \\
16,4\end{array}$ & $\begin{array}{l}22,8 \\
43,3 \\
62,6 \\
75,8 \\
40,9 \\
53,0 \\
45,7 \\
43,3\end{array}$ & $\begin{array}{l}36,9 \\
25,3 \\
52,6 \\
52,6 \\
26,8 \\
69,9 \\
45,4 \\
65,8\end{array}$ \\
\hline $\begin{array}{l}\text { Изучение } \\
\text { поверхности зерен } \\
\text { микрофоссилий } \\
\text { состава и текстур в шлифах } \\
\text { электропроводности } \\
\text { радиоактивности } \\
\text { плотности } \\
\text { естественной влажности } \\
\text { водопроводности }\end{array}$ & $\begin{array}{r}10,8 \\
6,0 \\
2,4 \\
4,8 \\
2,4 \\
13,2 \\
19,3 \\
13,2\end{array}$ & $\begin{array}{r}10,8 \\
5,1 \\
11,0 \\
8,0 \\
2,8 \\
29,5 \\
40,5 \\
19,5\end{array}$ & $\begin{array}{r}10,8 \\
18,1 \\
13,2 \\
9,6 \\
7,2 \\
19,3 \\
20,5 \\
15,7\end{array}$ & $\begin{array}{r}16,2 \\
14,5 \\
16,4 \\
4,0 \\
2,8 \\
23,1 \\
13,5 \\
26,0\end{array}$ & $\begin{array}{r}13,2 \\
20,5 \\
22,9 \\
8,4 \\
7,2 \\
19,3 \\
15,7 \\
15,7\end{array}$ & $\begin{array}{r}17,6 \\
14,5 \\
16,4 \\
4,0 \\
19,7 \\
15,4 \\
10,8 \\
11,7\end{array}$ & $\begin{array}{l}65,0 \\
55,4 \\
61,4 \\
77,0 \\
83,1 \\
48,2 \\
44,5 \\
55,4\end{array}$ & $\begin{array}{l}55,4 \\
65,9 \\
56,2 \\
84,0 \\
74,7 \\
32,0 \\
35,2 \\
42,8\end{array}$ \\
\hline
\end{tabular}


фракции в интервале $0,05-0,25$ мм. В европейских странах исследования легких и тяжелых минералов проводятся по песчаной и пылеватой фракциям в равной мере, а в североамериканских чаще ограничиваются только песчаной (табл. 2). На обоих континентах за границу между легкой и тяжелой подфракциями принимается обычно $2,9(2,89-2,91)$

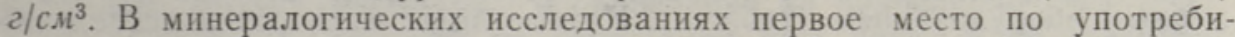
тельности занимает бромоформ $\left(\mathrm{CHBr}_{3}\right)$, второе - тетрабромэтан $\left(\mathrm{Br}_{2} \mathrm{CHCHBr} 2\right)$. Другие тяжелые жидкости используются только при решении специальных задач.

В качестве шкалы окатанности в Европе предпочитают шкалу Кайё $(18 \%)$, а в Северной Америке - шкалу Поуэрса (19,3\%). Применяется множество и других шкал, в том числе субъективные трех- (окатанные, полуокатанные, неокатанные), четырех- и пятибальные (идеально окатанные, хорошо окатанные, полуокатанные, слабо окатанные, неокатанные).

Из методов датирования отложений наиболее популярен радиоуглеродный. А такие методы, как палеомагнитный, аминокислотный, термолюминесцентный, урановый, выщелачивания карбонатов, применяют менее $5 \%$ исследователей. Палинологический анализ переотложенной пыльцы взят на вооружение лишь немногимн специалистами (14\% в Европе и менее $3 \%$ в Северной Америке).

Химические и геохимические методы нашли в европейских странах более массовое применение, нежели в североамериканских (табл. 2), особенно среди почвоведов и инженеров-геологов. Однако и здесь прослеживаются четкие региональные различия. Например, в Финляндии, в районах выходов кристаллических пород, определения карбонатности выполняются довольно редко, а в Польше, на выходах осадочных пород, напротив, очень широко $(85,7 \%)$. Исследования шлифов и микрофоссилий проводятся лишь при решении специальных задач.

Таблица 3

Использование лабораторного оборудования, \%

\begin{tabular}{|c|c|c|c|c|c|c|c|c|}
\hline \multirow{2}{*}{ Приборы } & \multicolumn{2}{|c|}{ Обычно } & \multicolumn{2}{|c|}{ Часто } & \multicolumn{2}{|c|}{ Редко } & \multicolumn{2}{|c|}{$\begin{array}{c}\text { Никогда не } \\
\text { исполь- } \\
\text { зуются }\end{array}$} \\
\hline & $\begin{array}{l}\text { Сев. } \\
\text { Aме- } \\
\text { рика }\end{array}$ & $\begin{array}{r}\text { Ев- } \\
\text { ропа }\end{array}$ & $\begin{array}{l}\text { Сев. } \\
\text { Аме- } \\
\text { рика }\end{array}$ & $\begin{array}{c}\text { EB- } \\
\text { porra }\end{array}$ & $\begin{array}{l}\text { Сев. } \\
\text { Аме- } \\
\text { рика }\end{array}$ & $\begin{array}{c}\text { Eв- } \\
\text { ропа }\end{array}$ & $\begin{array}{l}\text { Сев. } \\
\text { Аме- } \\
\text { рика }\end{array}$ & $\begin{array}{c}\text { Eв- } \\
\text { ропа }\end{array}$ \\
\hline
\end{tabular}

Микроскопы

бинокулярный

петрографический

биологический

электронный

сканирующий

Магнитный сепаратор

Приборы для определения кар-

бонатности

газометрический

химический

Пламенный фотометр

Атомный абсорбционный спектрограф

Установки

рентгеновская

флуоресцентная

термическая

термолюмннесцентная

$2^{*}$

$\begin{array}{rrrrrrrr}45,8 & 36,0 & 20,5 & 28,8 & 12,0 & 15,3 & 21,6 & 19,9 \\ 39,7 & 29,0 & 25,3 & 21,9 & 12,0 & 20,1 & 22,8 & 29,0 \\ 6,0 & 10,8 & 9,6 & 22,9 & 6,0 & 10,8 & 78,2 & 55,5 \\ 2,4 & 4,0 & 6,0 & 5,1 & 14,4 & 15,3 & 78,2 & 75,6 \\ 1,2 & 1,0 & 3,6 & 4,1 & 7,2 & 9,3 & 87,9 & 85,6 \\ 10,8 & - & 9,6 & 22,0 & 18,1 & 7,3 & 61,4 & 70,7 \\ & & & & & & & \\ 32,5 & 19,3 & 12,0 & 7,3 & 4,8 & 15,6 & 50,5 & 57,8 \\ 4,8 & 9,1 & 24,1 & 14,5 & 19,3 & 17,3 & 51,7 & 59,1 \\ 6,0 & 17,4 & 12,0 & 13,0 & 8,4 & 5,8 & 85,5 & 63,8 \\ 14,4 & 11,7 & 12,0 & 18,9 & 7,2 & 7,2 & 66,2 & 62,2 \\ 25,3 & 19,8 & 32,5 & 18,0 & 12,0 & 25,2 & 30,1 & 37,0 \\ 6,0 & 2,8 & 14,4 & 12,8 & 6,0 & 5,5 & 73,4 & 78,9 \\ - & 6,8 & 3,6 & 13,7 & 8,4 & 16,4 & 87,9 & 63,1 \\ - & 6,5 & - & 3,9 & 4,8 & 3,9 & 95,1 & 85,7\end{array}$


Необходимым оборудованием для литологических и минералогических анализов располагают главным образом геологи университетов и академий наук, и то редко. Многие лаборатории не оснащены, например, электронными и сканирующими микроскопами, атомными абсорбционными спектрографами, термолюминесцентной аппаратурой, т. е. современным оборудованием (табл. 3). Разные виды химических исследований выполняются прежде всего геологами и почвоведами, в чьем распоряжении имеются пламенные фотометры, рентгеновские и флюоресцентные установки. Инженеры-геологи обычно не заннтересованы в результатах литолого-минералогических и химических исследований и поэтому соответствующую аппаратуру используют довольно редко.

Хорошо известно, что общепринятых границ между гранулометрнческими фракциями в мире не существует. В силу давно сложившихся традиций полная унификация этих границ вряд ли реальна, но, без сомнения, вполне возможна хотя бы относительно таких широко распространенных фракций, как песок - пыль (алеврит), пыль - глина и т. д. Соглашение по этому вопросу будет иметь большое значение для международных корреляций и сравнения результатов исследований.

Большинство североамериканских исследователей ледниковых отложений пользуется размерными классификациями Уэнтворта или УСДА, предпочитая следующие верхние границы фракций: песок - гравнй 2,0 мм (92,8\% ответов), пыль - песок 0,062 мм (62,6\%), глина - пыль 0,004 мм $(37,3 \%)$ и 0,002 мм $(30,1 \%)$. Как видно, по первой фракцин мнения исследователей почти сходятся, по второй расходятся незначительно и лишь по третьей разделяются более или менее поровну (табл. 4).

В европейских странах картина стандартизации границ размерных фракций отличается большей пестротой. Это объясняется тем, что здесь существует множество различных гранулометрических шкал и наборов сит. На Варшавском совещании упомянутой выше Комиссии ИНКВА в 1975 году (Stankowski, 1976) были предложены для дальнейшего обсуждения следующие размерности верхних границ фракций: для глинистой 0,002 мм, для пылеватой $0,06(0,063)$ мм нли 0,1 мм, для песчаной 2,0 мм, для гравийной 10,0 или 20,0 мм, для галечной 6 или $10 \mathrm{~cm}$

Таблица 4

Рекомендуемые верхние границы гранулометрических классов

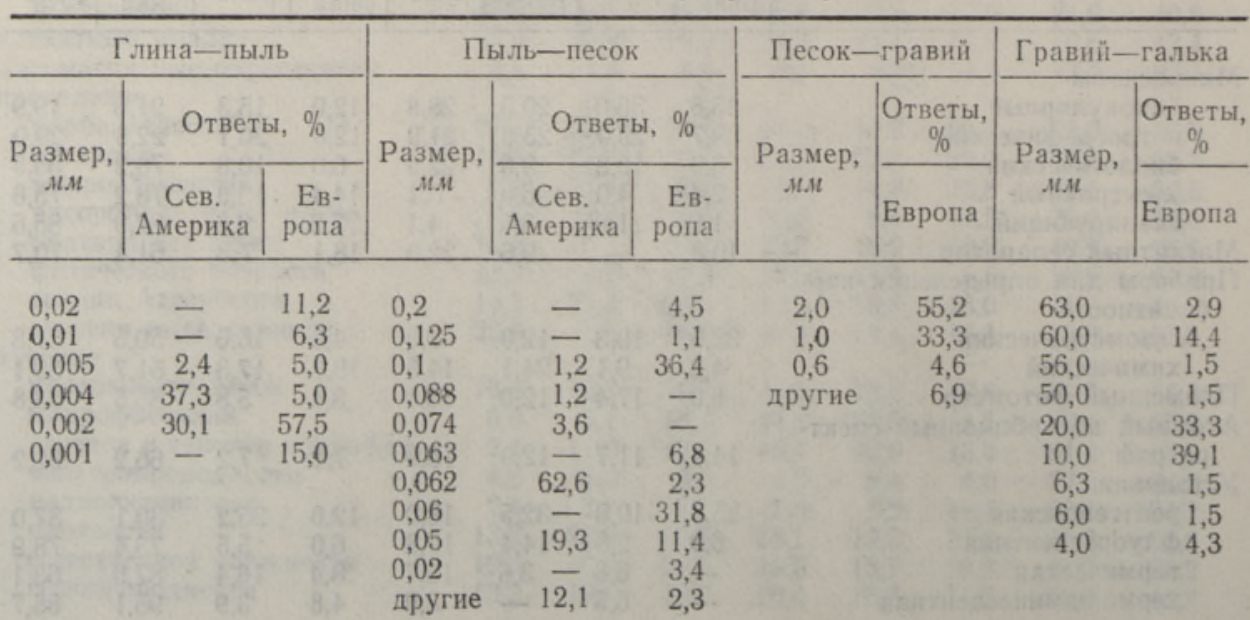


и для отломов 20 см. Многие исследователи выступили за использование $\varphi$-шкалы Крамбейна (Krumbein, 1934).

Учитывая большие различия в гранулометрических шкалах, мы считаем, что наиболее реальным путем для получения сравнимых результатов является расширение набора сит за счет включения в него сит с диаметром отверстий $\varphi$-шкалы и ориентация на приведенные в табл. 4 основные границы фракций, которые могут дать новые идеи для стандартизации гранулометрической шкалы. Для предварительного обсуждения мы предлагаем следующие верхние пределы фракций: 0,002 мм для глинистой, 0,06 мм для пылеватой и 2 мм для песчаной.

В лабораторных условиях гранулометрические исследования проводятся, как правило, с помощью набора сит и ротапов, хотя нередко практикуется и просеивание вручную (15,5\% ответов). Это объясняется не столько слабой механизацией лабораторий, сколько некачественностью многих типов ротапов. Исследованиями в Дорожном институте Швеции было установлено (Bäckman, Knutsson, 1973), что низкое качество ротапов является основной причиной того, что приходится прибегать к дополнительному просеиванию вручную, чтобы получить сопоставимые данные.

На обоих континентах при изучении мелких фракций большее предпочтение отдают гидрометрической аппаратуре, нежели пипеточным установкам или осадочным трубкам. Фотографические седиментометры, граниформаметры, механические и телевизионные счетные аппараты, автоматические сепараторы и центрифуги имеются лишь в немногих лабораториях (табл. 5).

Диспергирование до седиментометрического анализа мелких фракций осуществляется как механически, так и с помощью ультразвука, кипячения, химических реагентов (диспергатор Калгуна и др.). Последние широко используют почвоведы. В Европе при изучении бескарбонатных ледниковых отложений в качестве химического диспергатора чаще применяют соляную кислоту $(\mathrm{HCl})$, а при изучении карбонатных пирофосфат натрия $\left(\mathrm{Na}_{4} \mathrm{P}_{2} \mathrm{O}_{7} \cdot 10 \mathrm{H}_{2} \mathrm{O}\right)$.

таблица 5

Использование аппаратуры для гранулометрического анализа, \%

\begin{tabular}{|c|c|c|c|c|c|c|c|c|}
\hline \multirow{2}{*}{ Приборы } & \multicolumn{2}{|c|}{ Обычно } & \multicolumn{2}{|c|}{ Часто } & \multicolumn{2}{|c|}{ Редко } & \multicolumn{2}{|c|}{$\begin{array}{l}\text { Никогда не } \\
\text { исполь- } \\
\text { зуются }\end{array}$} \\
\hline & $\begin{array}{l}\text { Сев. } \\
\text { Аме- } \\
\text { рика }\end{array}$ & $\begin{array}{l}\text { Eв- } \\
\text { pona }\end{array}$ & $\begin{array}{l}\text { Сев. } \\
\text { Аме- } \\
\text { рика }\end{array}$ & $\begin{array}{l}\text { Eв- } \\
\text { pona }\end{array}$ & $\begin{array}{l}\text { Сев. } \\
\text { Аме- } \\
\text { рика }\end{array}$ & $\begin{array}{l}\text { Ев- } \\
\text { ропа }\end{array}$ & $\begin{array}{l}\text { Сев. } \\
\text { Аме- } \\
\text { рика }\end{array}$ & $\begin{array}{l}\text { Eв- } \\
\text { ропа }\end{array}$ \\
\hline $\begin{array}{l}\text { Ситовые наборы } \\
\text { Установки }\end{array}$ & 86,7 & 94,8 & 6,0 & 4,3 & 2,4 & - & 4,8 & 0,9 \\
\hline \begin{tabular}{l}
\multicolumn{1}{c}{ пипеточные } \\
гидрометрические \\
Осадочные трубки \\
Элутриаторы \\
Центрифуги \\
Диспергаторы
\end{tabular} & $\begin{array}{r}49,4 \\
55,4 \\
24,1 \\
2,4 \\
16,9\end{array}$ & $\begin{array}{r}25,0 \\
45,1 \\
18,4 \\
5,5 \\
6,7\end{array}$ & $\begin{array}{r}8,4 \\
10,8 \\
3,6 \\
1,2 \\
9,6\end{array}$ & $\begin{array}{r}23,2 \\
17,7 \\
10,5 \\
5,5 \\
14,4\end{array}$ & $\begin{array}{r}10,8 \\
8,4 \\
6,0 \\
4,8 \\
14,4\end{array}$ & $\begin{array}{r}18,1 \\
9,7 \\
5,3 \\
4,1 \\
11,1\end{array}$ & $\begin{array}{l}31,3 \\
25,3 \\
65,1 \\
91,5 \\
59,0\end{array}$ & $\begin{array}{l}33,7 \\
27,5 \\
65,8 \\
84,9 \\
67,8\end{array}$ \\
\hline $\begin{array}{l}\text { механические } \\
\text { ультразвуковые } \\
\text { химические } \\
\text { Ротапы } \\
\text { Фотографические седименто- }\end{array}$ & $\begin{array}{l}53,0 \\
26,5 \\
13,2 \\
68,6\end{array}$ & $\begin{array}{l}50,0 \\
14,5 \\
13,0 \\
74,6\end{array}$ & $\begin{array}{r}10,8 \\
12,0 \\
7,2 \\
15,7\end{array}$ & $\begin{array}{r}14,3 \\
7,9 \\
4,8 \\
8,5\end{array}$ & $\begin{array}{r}4,8 \\
10,8 \\
3,6 \\
2,4\end{array}$ & $\begin{array}{l}2,7 \\
6,6 \\
3,2 \\
1,4\end{array}$ & $\begin{array}{l}31,3 \\
50,5 \\
75,9 \\
13,2\end{array}$ & $\begin{array}{r}33,0 \\
71,0 \\
79,0 \\
15,5\end{array}$ \\
\hline $\begin{array}{l}\text { метры } \\
\text { Автоматическне сепараторы }\end{array}$ & $\begin{array}{l}1,2 \\
2,4\end{array}$ & $\overline{1,8}$ & $\begin{array}{l}1,2 \\
1,2\end{array}$ & $\begin{array}{l}1,8 \\
1,8\end{array}$ & $\overline{-}$ & $\overline{5,5}$ & $\begin{array}{l}97,6 \\
96,4\end{array}$ & $\begin{array}{l}98,2 \\
90,9\end{array}$ \\
\hline
\end{tabular}


Геотехнические измерения в большинстве случаев выполняются только инженерами-геологами. Все же пределы Аттерберга, плотность и естественную влажность часто определяют специалисты и других профессий. Однако используемая ими для этих целей рутинная методика очень сильно отличается в разных странах, институтах и ведомствах. Поэтому результаты соответствующих исследований практически не подлежат сравнению, а стандартизация методов вряд ли оказывается возможной.

Несмотря на столь серьезные расхождения, в сводном процентном выражении ответы европейских и североамериканских исследователей удивительно совпадают, что указывает на благоприятные предпосылки для проведения международных геологических корреляций и унификации методов исследования. Однако при унификации методик встреча с серьезными трудностями неизбежна. Причин для этого несколько. Выше уже отмечалось, что ледниковые отложения изучаются в разных целях: для решения вопросов стратиграфии и палеогеографии (коррелирование разрезов, восстановление климатов прошлого, установление питающих провинций, характера и путей переноса обломочного материала и т. д.), выяснения генезиса отложений, степени и характера вторичных их изменений, определения качества отложений как минерального сырья, изучения естественного плодородия почв и характера процессов почвообразования, изучения отложений как строительных оснований и т. д.

Каждый из перечисленных вопросов требует специфических методов опробования, анализа и обработки данных. Полная унификация этих методов не всегда возможна также из-за различного характера объектов исследования и не всегда целесообразна в силу давно сложившихся традиций исследования в той или иной стране.

В данном обзоре мы лишь ограничились констатацией того, какими методами и какими приборами изучаются в настоящее время ледниковые отложения в разных странах. Что же касается рекомендаций для унификации каких-либо методов или видов анализа, мы их изложим в одной из следующих публикаций.

\section{Л ИТ Е Р А Т Р А}

B ä ckman, L, K nuts s o n, G. Undersökning ar olika siktapparates effektivitet. The National Road and Traffic Institute; Internrapport, N 121. Stockholm, 1973. Krumbein, H. C. Size frequency distribution of sediments. - J. Sediment. Petrol., 1934, N 4.

Stankowski, W. (ed.). Till, its genesis and diagenesis Univ. A. Mickiewicza, Poznan. Ser. Geografia, 1976, N 12.

Ннститут геологии

Академии наук Эстонской ССР

Университет Висконсин-Мадисон, США

Университет Западного Онтарио, Канада
Поступила в редакцию 3/II 1978 


\section{EUROOPAS JA PÖHA-AMEERIKAS KASUTATAVAD LIUSTIKUTEKKELISTE SETETE VALI- JA LABORATOORSED UURIMISMEETODID}

Liustikutekkeliste setete uurimise meetodite ja aparatuuri nüüdisseisu hindamiseks korraldas Rahvusvahelise Kvaternaariuurimisliidu (INQUA) setete geneesi ja litoloogia komisjon küsitluse, mille olulisemad tulemused on toodud tabelites 1-5. Vaatamata aparatuuri ja meetodite üsna suurele varieeruvusele üksikutes maades ja erinevate teadusharude esindajate vahel, erinevad keskmised näitajad mõlemal kontinendil siiski üsna vähe, mis loob head eeldused uurimismeetodite edasiseks ühtlustamiseks ja standardiseerimiseks.

\section{METHODS OF THE FIELD AND LABORATORY INVESTIGATIONS OF GLACIAL DEPOSITS IN EUROPE AND NORTH AMERICA}

On behalf on the INQUA Commission on Genesis and Lithology of Quaternary Deposits, a detailed questionnaire consisting of about 150 questions concerning the methodology of investigations of glacial deposits was distributed in the formerly glaciated countries of Europe and North America. Over 200 replies representing about 1000 investigators of glacial deposits (geologists, geographers, pedologists, soil engineers) are summarized and discussed (Tables 1-3). Particular attention is paid to the particle-size determinations and their boundaries (Tables 4,5 ). Though the methods and equipment used vary considerably among the specialists of different professions and different countries, surprisingly few major differences exist between the average data of Europe and North America. 